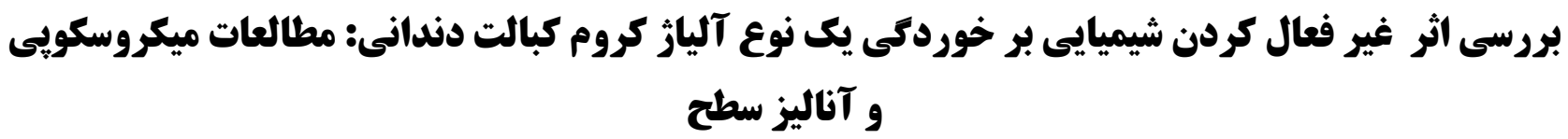

\author{
دكتر الناز مصلحى فرد' \\ ا- دانشيار يروتزهاى دندانى، تروه يروتزهاى دندانى، داني، دانشكده دندانيز شكى دانشكاه علوم يزشكى تبريز
}

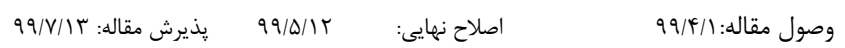

\title{
Effect of surface passivation on corrosion of a cobalt-chromium dental alloy: surface morphology and chemical composition studies
}

Elnaz Moslehifard ${ }^{1}$

1-Associate Professor, Department of Prosthodontics, Faculty of Dentistry, Tabriz University of Medical Sciences, Tabriz, Iran

\section{Abstract}

Received: July 2020 ～～～Accepted: Sep 2020

Background and Aim: Biocompatibility in some respects depends on the corrosion behavior of dental alloys. The purpose of this study was to investigate the effect of surface passivation of a cobalt chromium alloy on corrosion behavior.

Materials and methods: In this experimental study, 20 samples of Flexicast dental alloy were prepared according to ADA97 standard and after casting, the samples were polished to the mirror surface. Electrolytic passivation was employed by immersion of one first series of samples in Na2SO4 solution for 24 hours at room temperature. The second series of specimens was not passivated. Surface morphology and chemical composition before and after passivation studied by scanning electron microscopy and energy-dispersive X-ray spectroscopy were used to investigate the corrosion behavior in saline solution. Corrosion test was conducted for 4 weeks and surface of specimens were monitored each week. The chemical composition results were analyzed by Kruskal-Wallis and Mann-Whitney tests using SPSS17 software.

Results: The passivated specimens exhibited higher corrosion resistance while pitting corrosion was detected in all specimens. Kruskal-Wallis test showed a significant difference between the two groups of passivated and non-passivated samples. The Mann-Whitney test showed that the cobalt, chromium and oxygen ions were significantly different between the two groups $(\mathrm{P}<.05)$.

Conclusion: The rate of corrosion and formation of pits were significantly reduced by surface passivation.

Key words: cobalt-chrome alloy, corrosion, chemical passivation

*Corresponding Author: elnaz_moslehi@yahoo.com

J Res Dent Sci.2021;17(4): 296-304 
خلاصه:

سابقه و هدف: يكى از عوامل مهم در زيست سازكارى خاصيت مقاومت به خوردگى آليازهاى دندانى است. هدف اين مطالعه، بررسى

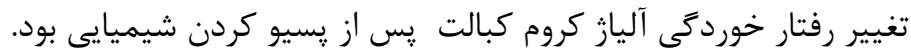

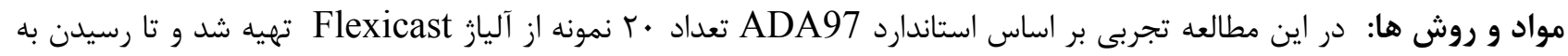

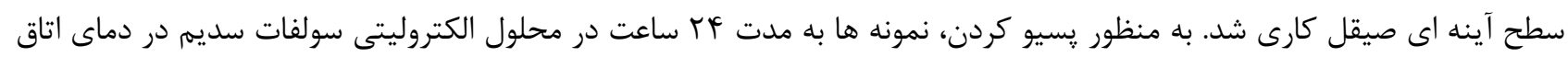

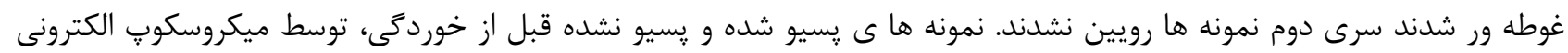

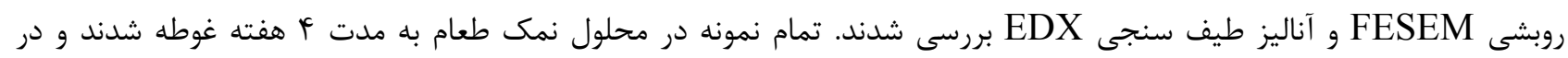

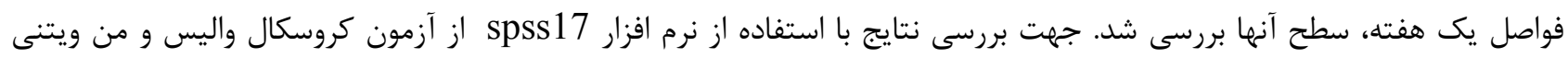
استفاده شد.

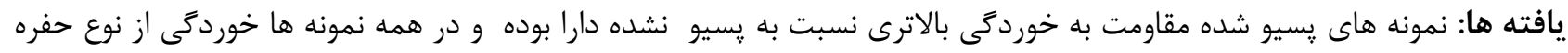

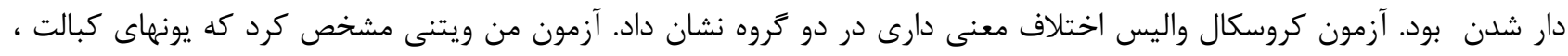

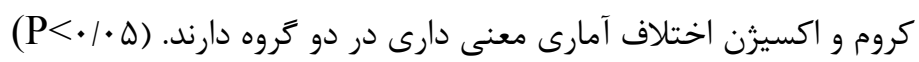

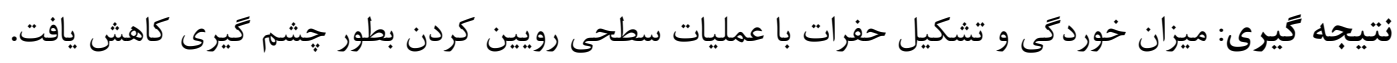

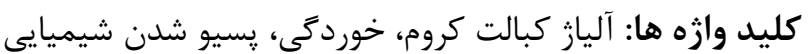

تخريب آن مانند شكستن ناحيه لحيم شده كَرد. از نقطه نظر مقدمه: زيبايى نيز كدرشدن سطوح فلزى باعث بد نما شدن رستوريشن آلياز هاى ريختخى متعددى جهت استفاده درساخت يروتزهاى خواهد شد. به عنوان يك قانون كلى، هر آلياز دندانى در محيط

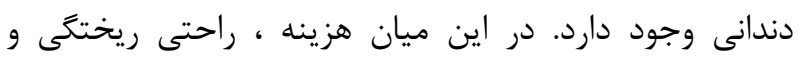
دهان در نتيجه شرايط دهانى در معرض خوردگى قرار خواهد

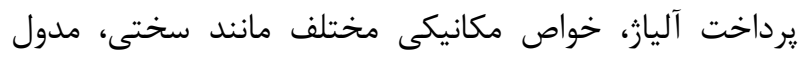
كرفت. بنابراين بايد تا حد امكان از آلياز هاى با حداقل آزاد

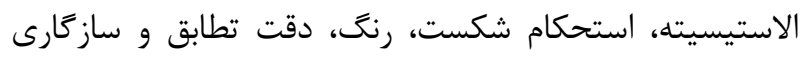

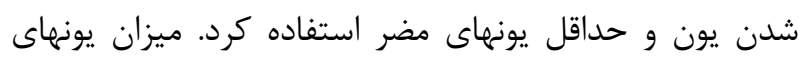

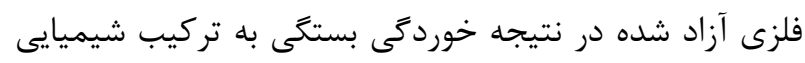

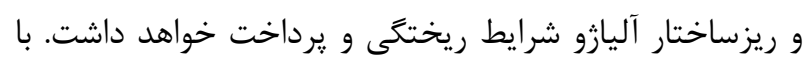
اينحال شرايط خاص و متفاوت محيطهاى دهان مانند بزاق،

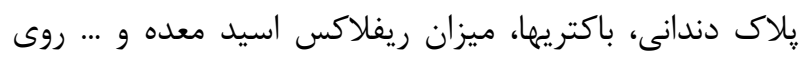

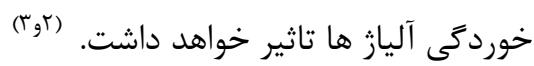
يسيو شدن يا غيرفعال شدن (Passivity) سطح فلزى در

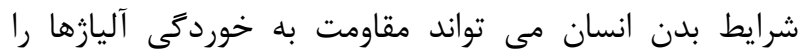
بهبود ببخشد .يسيو شدن شرايطى است كه با تشكيل يك لايه

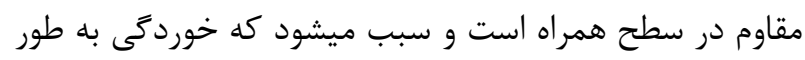
قابل ملاحظه اى كاهش مى يابد. اين امر در نتيجه تشكيل همر داه

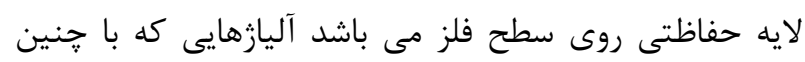
نسجى آليازها در انتخاب يك آلياز مناسب مهمه مى باشند.

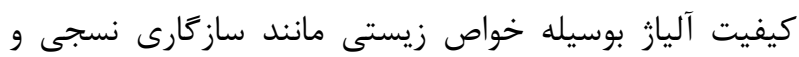

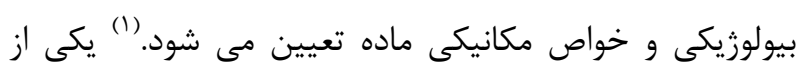

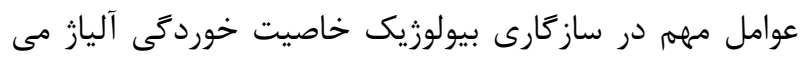
باشد. خوردكى باعث آزاد شدن يونهاى فلزى شده و اين يونها در تماس مستقيم با سلولها و بافتها خواهند بود يا به دنبال جذب در كل بدن يخش خواهند شد. در صورتى كه اين يونها با

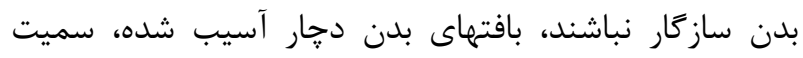

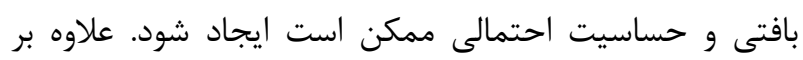

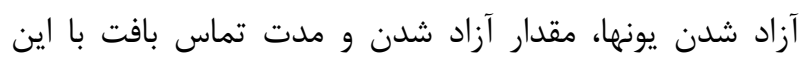

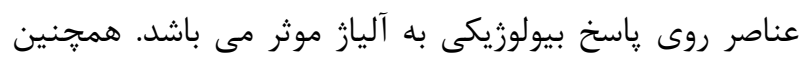

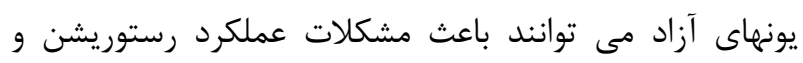


لايه هايى يوشيده شده باشند رتانسيل الكتروشيميايى نجيب ير ترسي

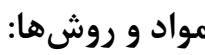

دراين مطالعه تجربى و آزمايشگاهى بر اساس . Specification No.97-2002 استفاده از ديسك پِلاستيكى الكَوهايى به قطر8 ميليمتر وضخامت 1 ميليمتر تهيه شد. الكوى پِلاستيكى اسيرو كذارى لرى شده و با اينوستمنت با بيس فسفات ( Deguvest L, Degudent GmbH, Rodenbacher, (Germany)|ينوست شده و مطابق دستورات كارخانه حذف Rom موم انجام شد. با استفاده از دستخاه سانتريفوز و با تورج كاز اكسيرن (Motorcast, Degussa, Germany) آلياز Flexicast All,Glendale CA, USA

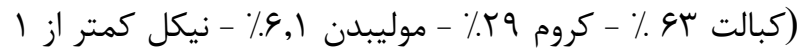
\% - سيلسيوم كمتر از 1 \% ) مي باشد. يس از ريختكى نمونه

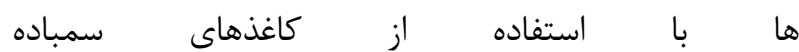
Sand Paper 991 A, )(\#A..\#A...\#ץ...\#rr.) Softflex, Wasserfest,Germany خمير يرداخت (Bego, Bermen, Germany) تا رسيدن به سطح آينه اى گاليش شد.

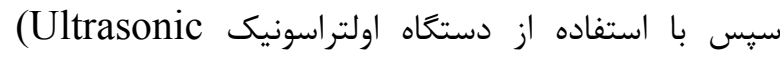
Prpcessor, Hiescher, Germany ) مدت • ا دقيقه تميز شدند. الكل يرويانول •V٪ و هواى داغ • • له درجه سانتيخراد براى آماده سازى نهايى نمونه ها بكار

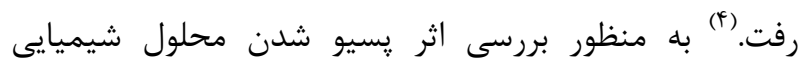

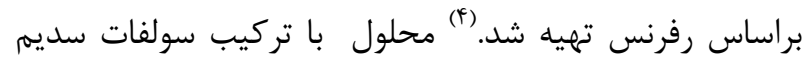

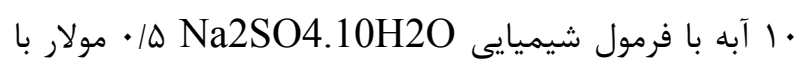

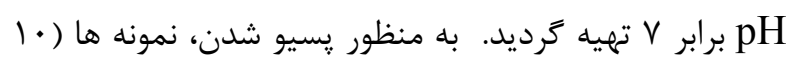

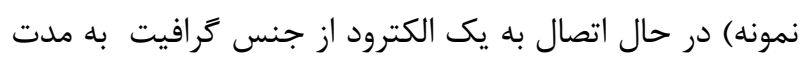

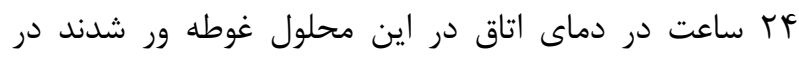

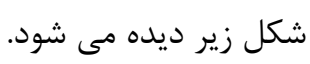

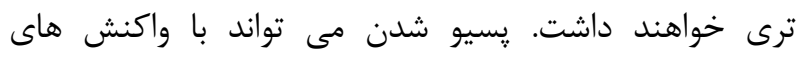

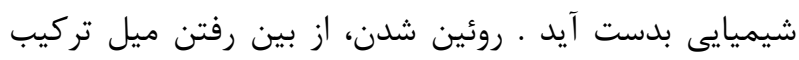

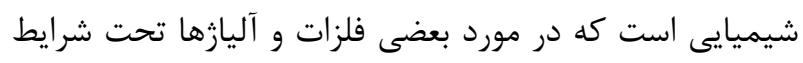
معينى بوجود مى آيد. بدين معنى كه بعضى فلزات و آليازها تقريبا نجيب و خنثى شده وطورى رفتار مىكنند كه كويا فلزات نجيبى مانند پِلاتين و طلا هستند. اين امر در نتيجه تشكيل لايه حفاظتى روى سطح فلز مى باشد آليازهايى كه با ليا جنين لايه هايى يوشيده شده باشند يتانسيل الكتروشيميايى با

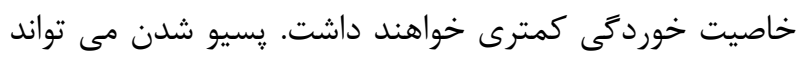
با واكنش هاى شيميايى بدست آيد . لايه هاى يسيو هدايت

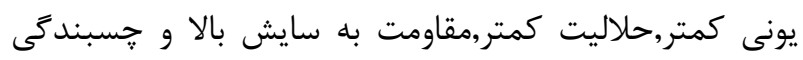

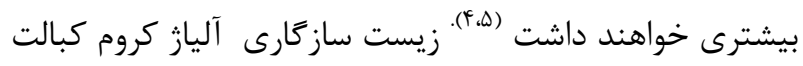
با مقاومت بالا به خوردكى مرتبط است كه در نتيجه تشكيل

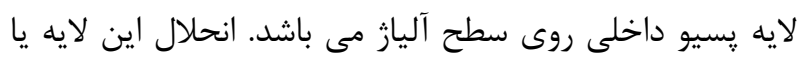

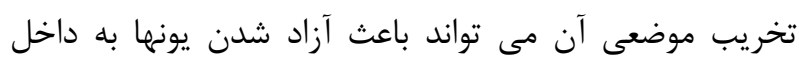

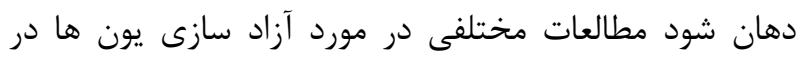
نتيجه خوردكى در آليازهاى بيس متال وجود دارد طبق مطالعه Matkovic

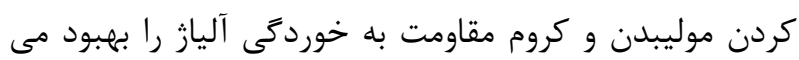
بخشد .در مطالعات ديكر با كاهش كروم به ميزان كمتر از معاز 19

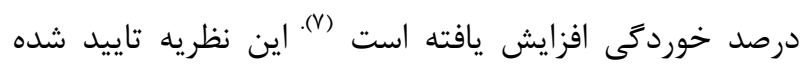

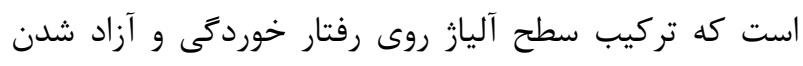

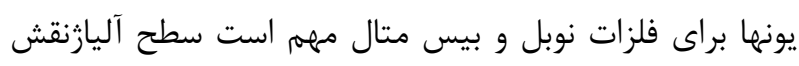

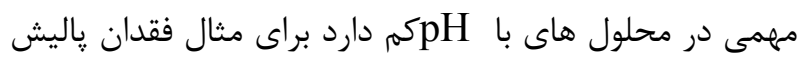

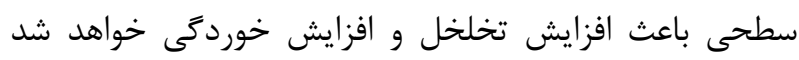

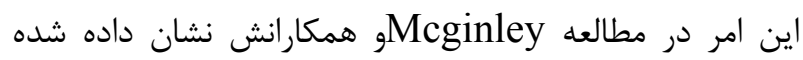
است. (^) مطالعات اندكى در مورد خواص الكتروشيميايى آلياز و دماله بررسى و بهينه كردن سطح آن وجود دارد. اغلب مطالعات موجود روى مقاومت به سايش و خراش اين آلياز انجام شده است. هدف از اين مطالعه، يسيو كردن آليازكروم كبالت موليبدن و بررسى خصوصيات سطحى آن مى باشد. 
تغييرات غلظت عناصر مختلف شامل عناصر آلياز مورد نظر و

$$
\text { اكسيزن و كلر بررسى شد. }
$$

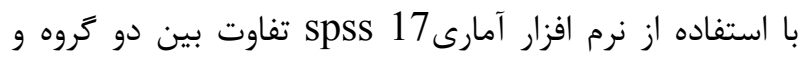
تفاوت يونهاى موجود در سطح نمونه ها با آزمون آمارى بـ درم

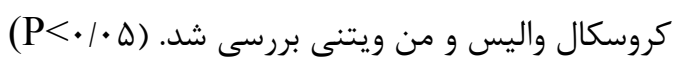

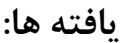

تصويرميكروسكويى نمونه هاى يسيو نشده و پسيو شده قبل از

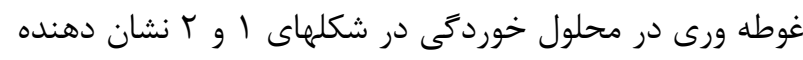

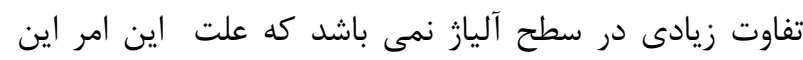

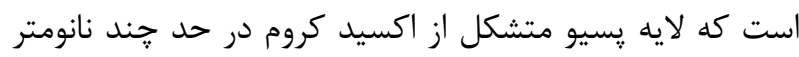

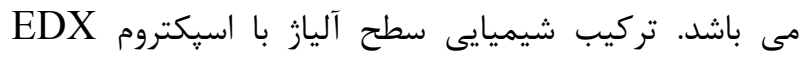
نشان دهنده وجود اكسيرن در سطح نمونه هاى يسيو شده بود.(نمودار ()

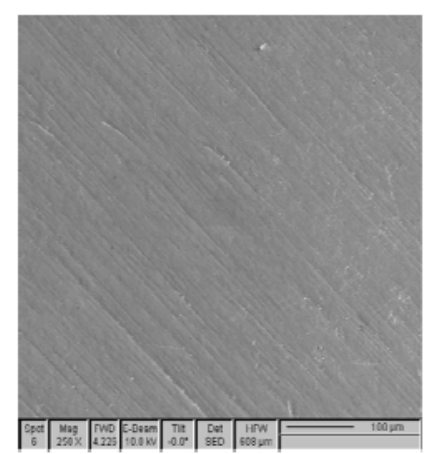

شكل ا -تصوير ميكروسكويى نمونه هاى بسيو نشده قبل از غوطه

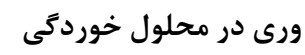
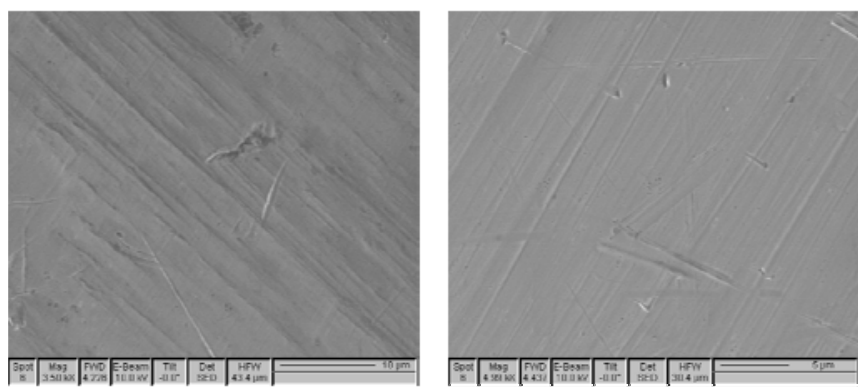

شكل r -تصويرميكروسكويى نمونه هاى بسيو شده قبل از غوطه

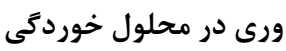

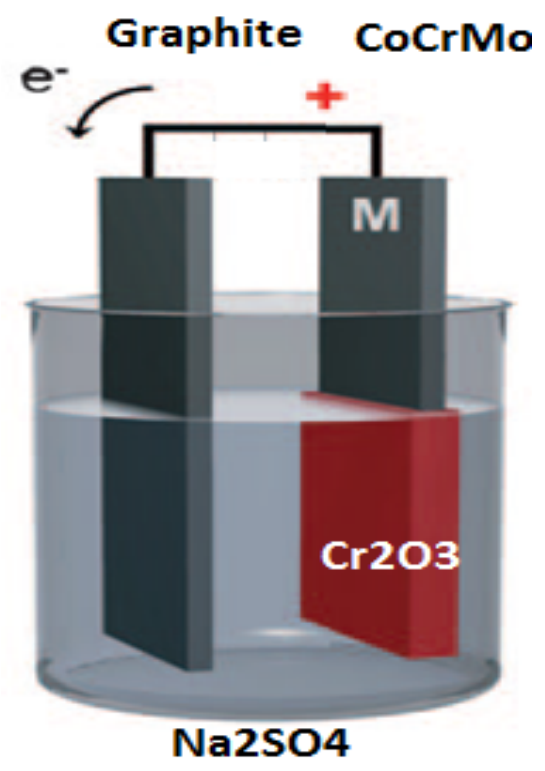

شكل - روش يسيو كردن نمونه ها

در اين شكل غوطه ورى نمونه ها در محلول سولفات سديم

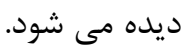
لايه يسيو ايجاد شده اكسيد كروم مى باشد (f) زمان ،دما و نوع محلول در روند يسيو شدن مهم است. سرى دوم نمونه ها

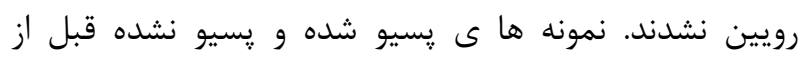

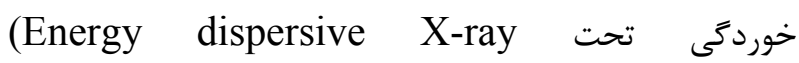
FESEM,EDX spectroscopy) نمونه هاى يُيوشده و نشده در محلول نرمال سالين به مدت

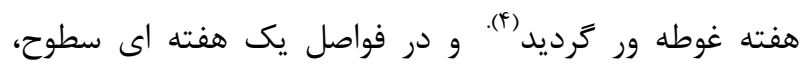
مورد بررسى مجدد قرار گرفتند بررسى اثر خوردىى بر روى تغيير مورفولوزى سطح و همجنين تركيب شيميايى آلياز در اين مطالعه مورد نظر بوده است. به منظور شست و شو ، نمونه

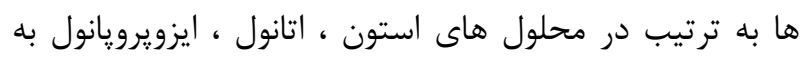

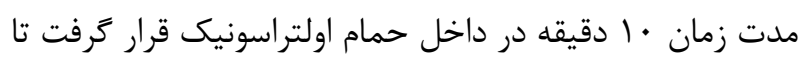

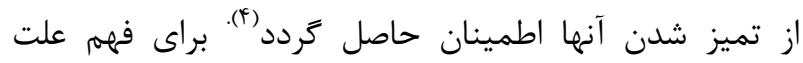
خوردكى، لاين اسكن روى خط فرضى SEM انجام كرفت و 


\section{سطح نمونه يِيو نشده}

سطح نمونه يسبو شده

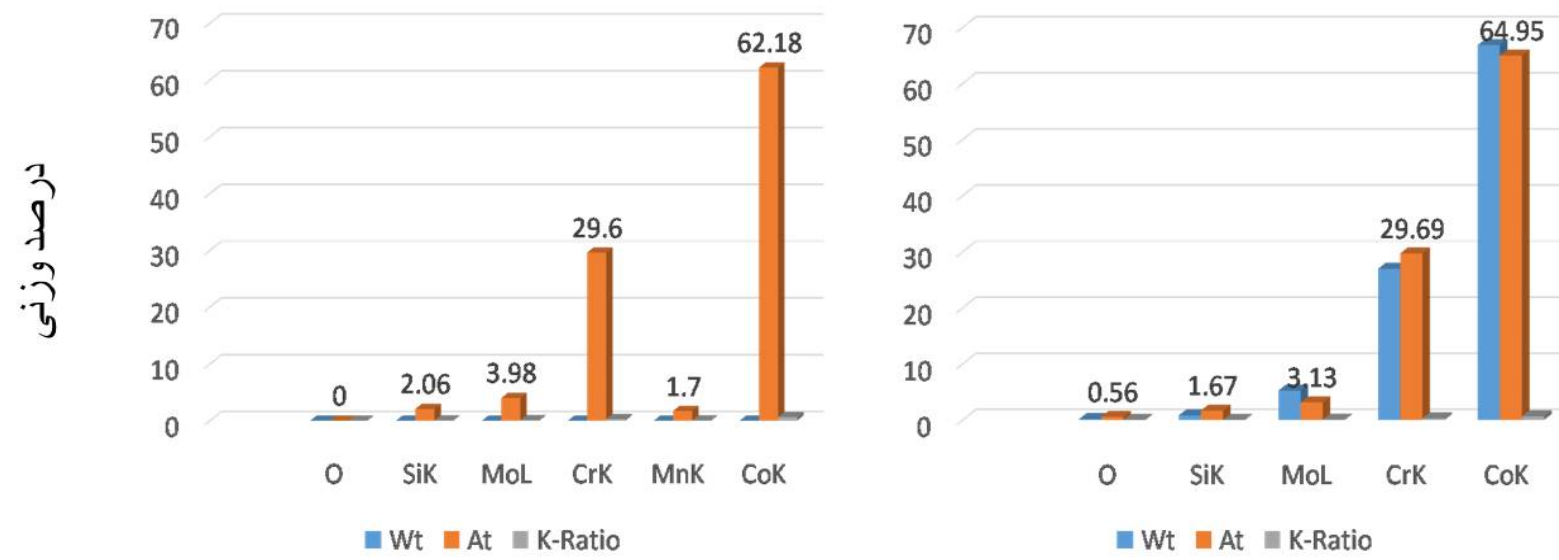

نمودار 1- تركيب شيميايى سطح آلياز نمونه هاى يسيو نشده و يسيو شده

براى اطمينان از تشكيل لايه بسيو، تصوير عنصرى سطح و تصوير

الكترون برگشتى كرفته شد و اين تصاوير نشان داد نمونه يسيو

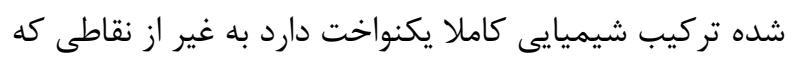
فازهاى كاربيدى ناشى از عيب ريخته كرى حين ريختن آلياز ديده

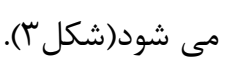

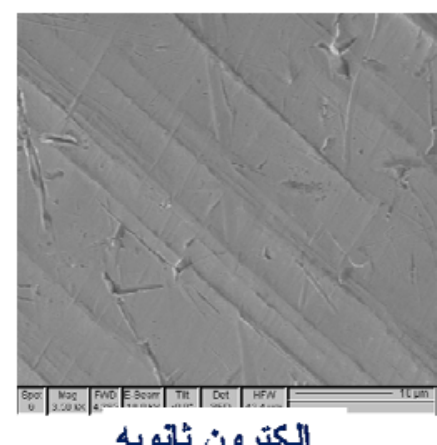

الكترون ثاتويا

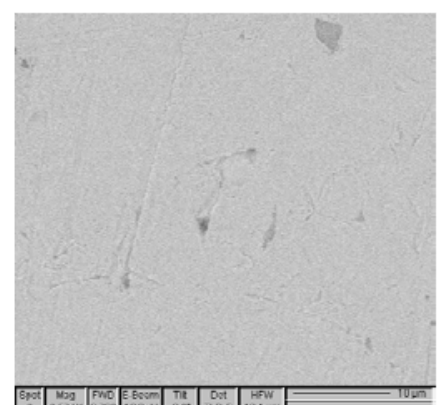

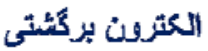

شكل r- تصوير ميكروسكويى الكترونى ثانويه و برَشتى از سطح نمونه يسيو شده

در شكل f نقشه عنصرى سطح نمونه يسيو شده نشان دهنده وجود اكسيرن سطح مى باشد. مورفولوزى سطح نمونه هاى يسيو نشده و يسيو شده پِ از غوطه ورى در محلول خوردىى طى جهار هفته در شكل ه نشان دهنده وجود حفرات خوردگى بيشترى در سطح

ميزان وجود يونها در دو گروه در جدول ا نشان داده شده است. و آزمون كروسكال واليس اختلاف معنى دارى در دو گروه نشان داد. آزمون من ويتنى مشخص كرد كه كبالت ، كروم و اكسيزن اختلاف

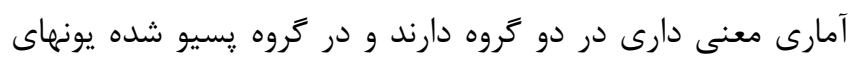

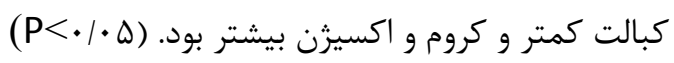

جدول ا- يونهاى سطح آلياز نمونه هاى يسيو نشده و يسيو شده بعد

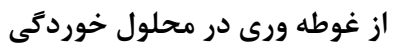

\begin{tabular}{|c|c|c|c|}
\hline Pvalue & 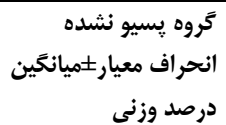 & 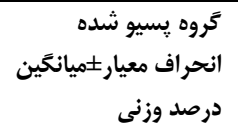 & يونها \\
\hline $\mathrm{P}=\cdot / \cdot \mathrm{r}$ & $9 r / \wedge \Lambda \pm r$ & $\Delta q / 9 \Delta \pm T^{4}$ & كبالت \\
\hline $\mathrm{P}=. / .1$ & $r q / q \pm r / \Delta$ & $r r / \Delta \pm r$ & كروم \\
\hline $\mathrm{P}=.1 .9$ & $r / 9 \wedge \pm \cdot / \Delta$ & $r / / r \pm \cdot / \Delta$ & موليبدن \\
\hline $\mathrm{P}=. / .9$ & $r \cdot 19 \pm / V$ & $1 / 9 \pm \cdot / r$ & سيليسيوم \\
\hline $\mathrm{P}<\cdot / \cdot \cdot 1$ & 0 & $\cdot / \Delta 9 \pm \cdot / r$ & اكسيرن \\
\hline
\end{tabular}


براى فهم علت peM ،لاين اسكن روى خط فرضى صورت كرفت و تغييرات غلظت عناصر مختلف شامل عناصر آلياز مورد نظر و اكسيزن و كلر مشخص شد. در حفرات درصد كروم بشدت كم و حضور كلر مشهود بود و نتيجه كرفته شد كه علت شكسته شدن لايه يسيو و محافظ است. علت تشكيل حفره، حمله يونهاى كلر موجود در نرمال سالين بود. در حفره ،كلر مشهود بوده و درصد اكسيرن به دليل شكسته شدن لايه پسيو كم بود. در لايه يسيو كلر وجود نداشته و اكسيرن زياد بود. تصوير ميكروسكويى و آناليز عنصرى سطح يسيو و حفره نمونه يسيو شده در شكل 9 نشان داده شده است. آزمون آمارى من

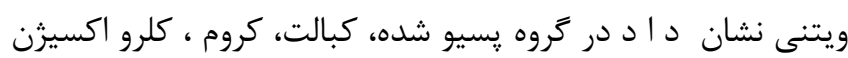
اختلاف معنى دار بين سطح و حفره د اشتند. (ه.|• إن م) دركروه يسيو نشده كروم و كلر اختلاف معنى دار بين سطح و حفره داشتند.
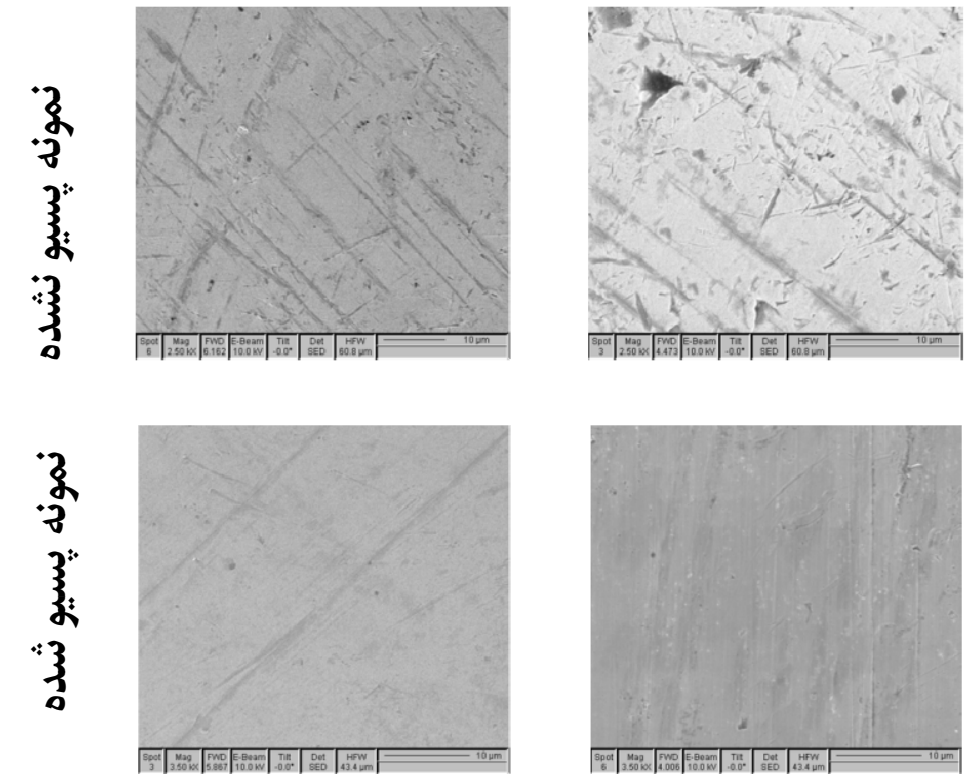

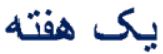

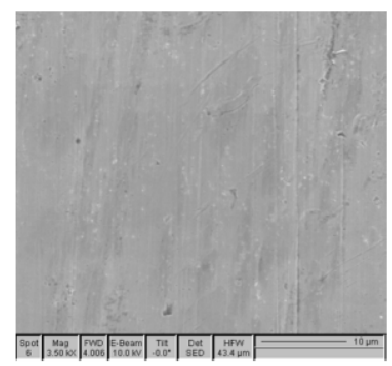

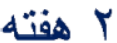

نمونه هاى يسيو نشده مى باشد. نمونه هاى يسيو شده مقاومت به خوردگى بالا و در همه نمونه ها خوردگى از نوع حفره دار

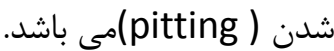
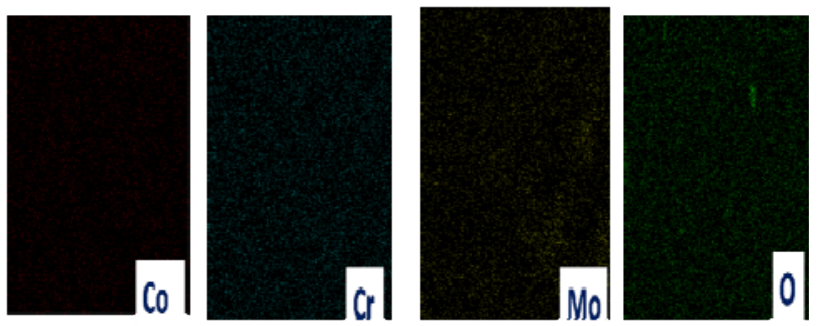

شكل †ـ نقشه عنصرى سطح نمونه بسيو شده
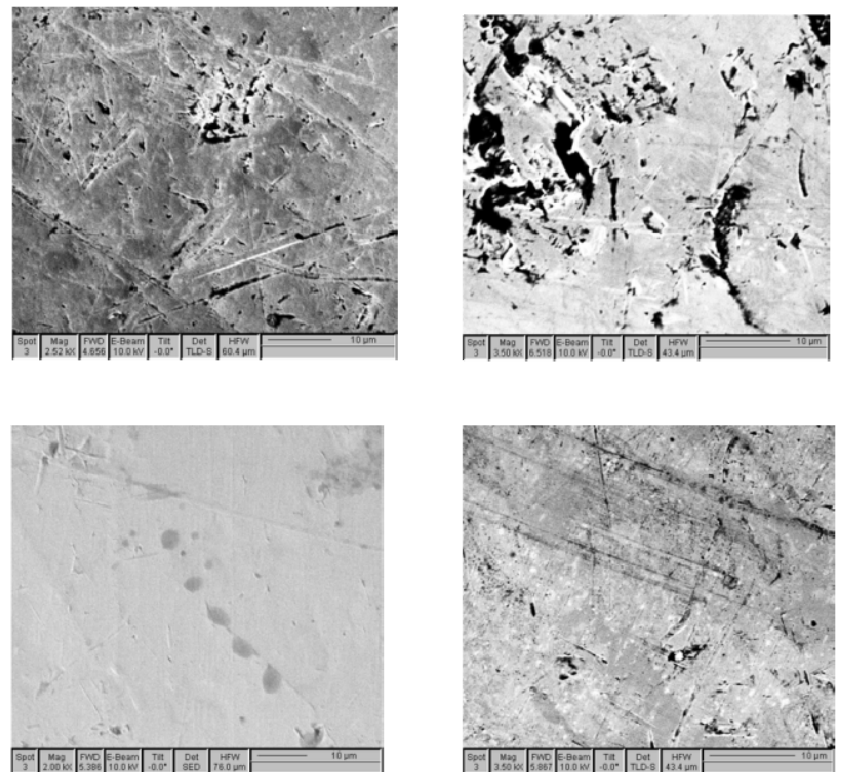

r هiته

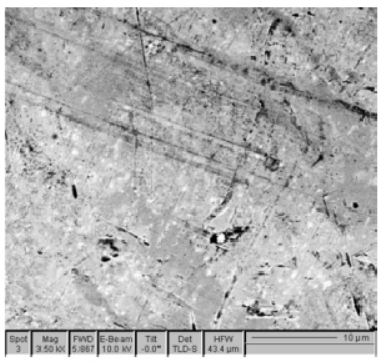

P

شكل هـ - مورفولوزى سطح نمونه هاى پيسيو شده و يسيو شده يِ از غوطه ورى در محلول خوردكى 
عناصر موجود درحفره
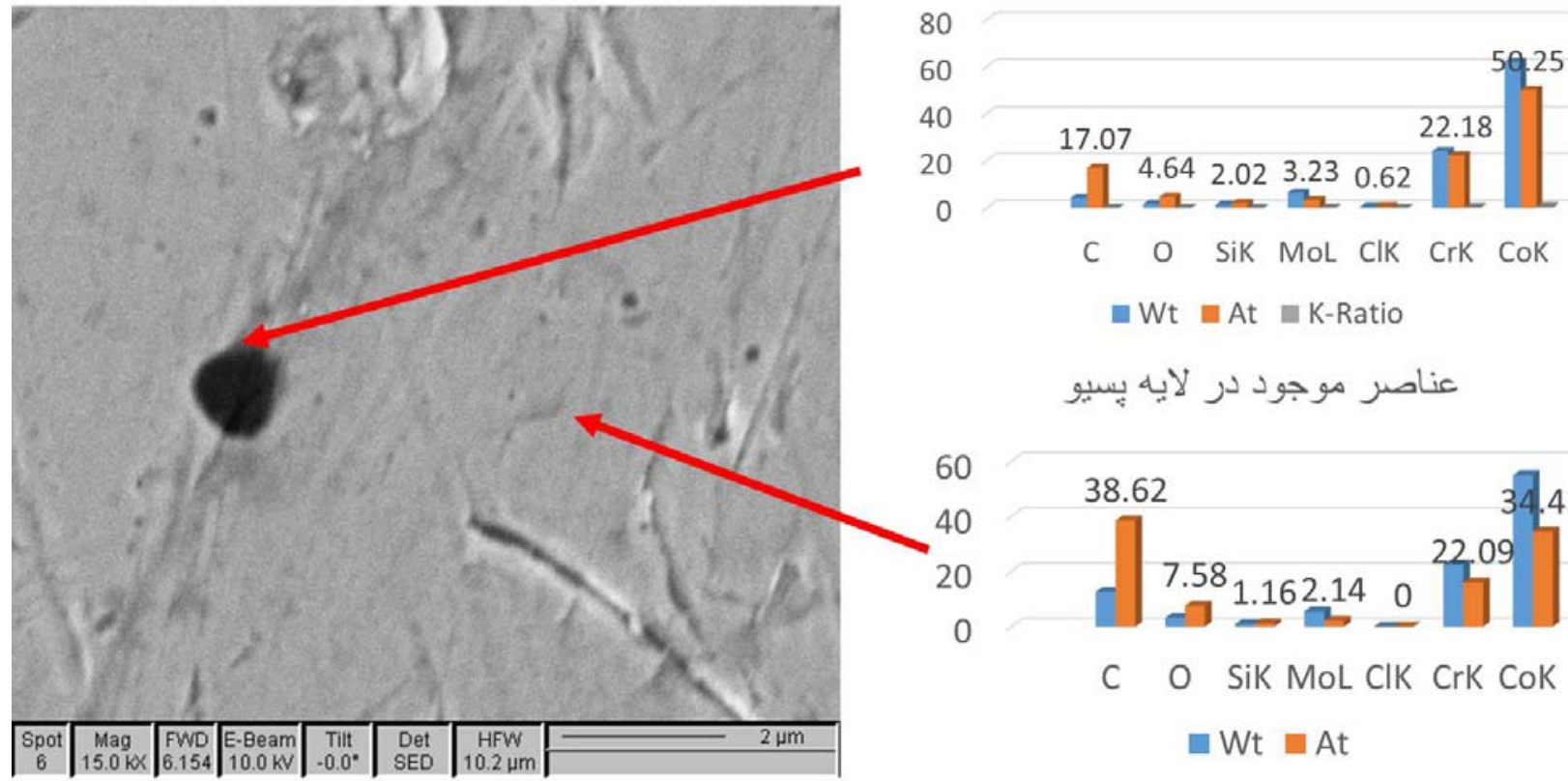

C O SiK MoL ClK CrK CoK

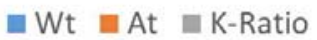

عناصر موجود در لايه بسيو

\section{0 \\ 40 \\ 0}

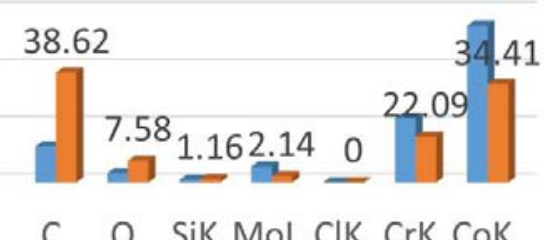

C O SiK MoL ClK CrK CoK $\square \mathrm{Wt}=\mathrm{At}$

شكل V- تصوير ميكروسكويى و آناليز عنصرى سطح پسيو و حفره نمونه يسيو شده

كرد. ميزان يونهاى فلزى آزاد شده در نتيجه خوردگى بستخى خوردَى باعث آزاد شدن يونهاى فلزى شده و اين يونها در تماس به تركيب شيميايى و ريزساختار آليازو شرايط ريختكى و ونئه

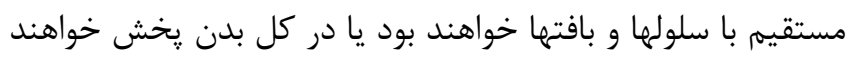
يرداخت خواهد داشت. محصولات خوردگى آليازهاى دندانى حاوى يونهاى فلزى بوده و مى توانند علت آلرزى و مشكلات سازكارى نسجى باشند و همجنين مى توانند باعث آسيب به وله

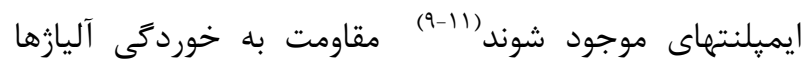
بستخى به لايه اكسيد يسيو (passive) نازى دارد. براى مثال

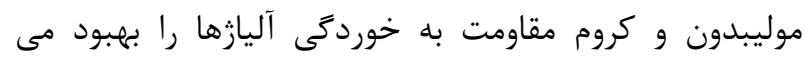
بخشد. يسيواسيون به فرآيند شيميايى يا الكتروشيميايى كفته

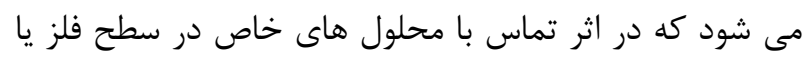
آلياز هاى خاص لايه اكسيدى نازك تشكيل مى شود. تشكيل

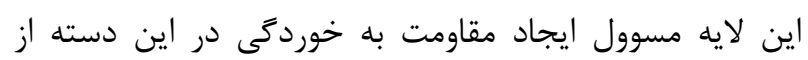

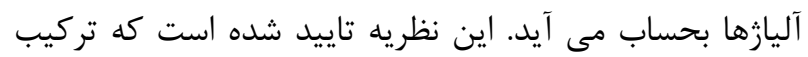

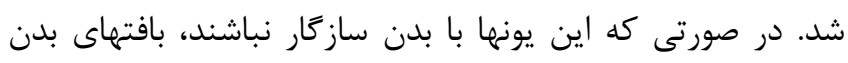

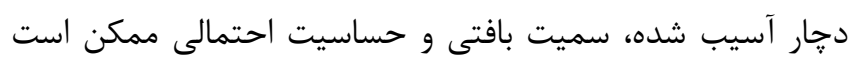

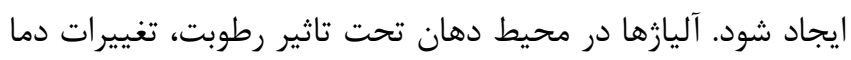

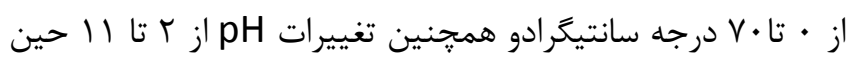

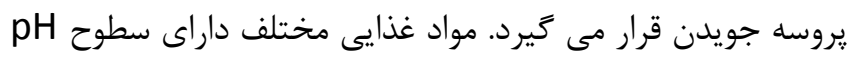

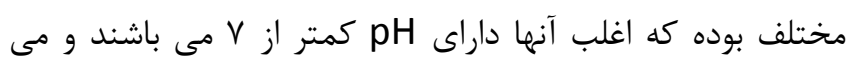

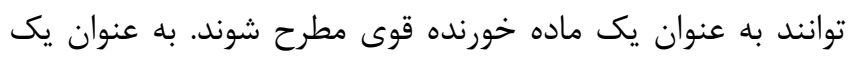

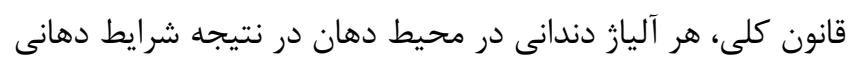

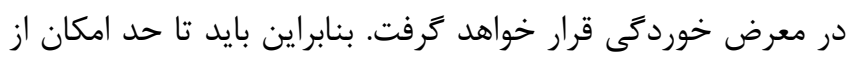
آلياز هاى با حداقل آزاد شدن يون و حرد حداقل يونهاى مضر مرد استفاده

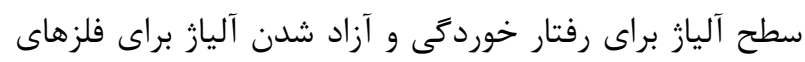

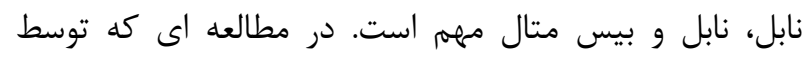
Denizoglu 
سديم مقاومت به خوردگى الكتروشيميايى آلياز را افزايش نمى

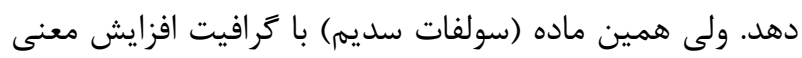
دارى را در مقاومت به خوردىى دارد. اين محققين در مطالعات SEM در برابر خوردگى حفره دار را افزايش مى دهد. همجنين نمونه هاى يسيو شده هيج نشانه اى از ترك خوردكى را نيز نشان

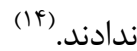
Jakovljević آلياز CoCrMo براى بهبود خواص خوردگى و كاهش انتشار يون هاى فلزى استفاده كردند .نتايج به دست آمده با روشهاى الكتروشيميايى، مقاومت به خوردگى بهتر نمونه هاى / TiN CoCrMo

نشان داد. Ragone يوشش TiNbN بر ميزان خوردگى آلياز كبالت-كروم-موليبدن انجام دادند .نتايج ميكروسكوٍ الكترونى روبشى نشان داد كه غلظت يونهاى فلزى آزاد شده از سطح يروتز يوشيده شده با دTiNbN اى كمتر بود ـ اين نتايج با بوشش لايه سيليس كربن نيز نشان

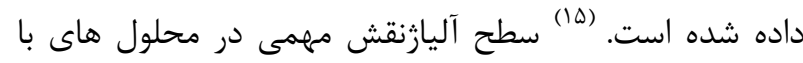
Sم دارد براى مثال فقدان پاليش سطحى باعث افزايش

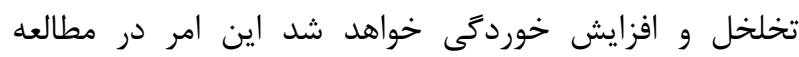
Mcginley بر קايه مطالعات انجام شده با استفاده از روش هاى هآ آناليز سطح و ميكروسكوب الكترونى براى آلياز كروم كبالت موليبدن مشخص گرديد كه نمونه هاى آلياز يس از قرار دادن در محلول سولفات سديم رويين شده و لايه اى از اكسيد كروم و بطور جزئى موليبدن سطح را بطور يكنواخت يوشانده است. مكانيزم خوردگى در اين آليازها از نوع موضعى بوده و با تشكيل حفرات

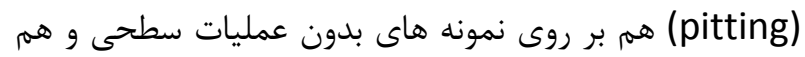

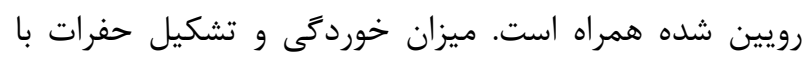

آلياز بيس متال در سطوح مختلف pH F و ه و V ارزيابى شد

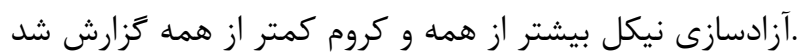

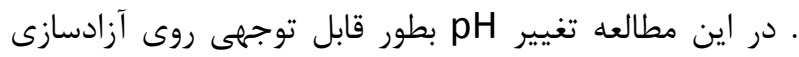
كلى آلياز و عنصر كبالت تاثير داشت ولى روى آزادسازى نيكل يا كروم موثر نبود همجنين نوع آلياز در آزادسازى عناصر

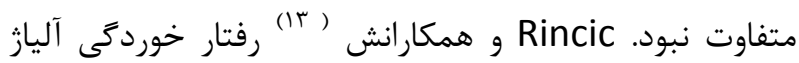

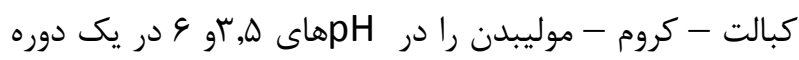
يك ماهه مطالعه كردند نتايج آنها نشان داد كه يون هاى كبالت كروم آهن روى و نيكل آزاد شدند و نوع pH مدت زمان غوطه ورى در اين آزادسازى موثر بود اين امر در مطالعه Mutlusagesen آلياز نقش مهمى در محلولهاى با pH كم دارد.براى مثال،

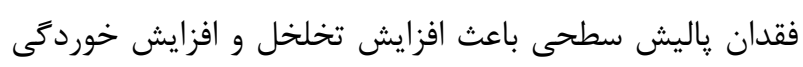

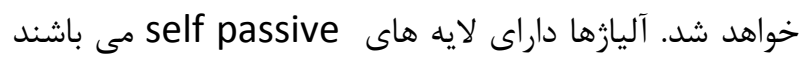

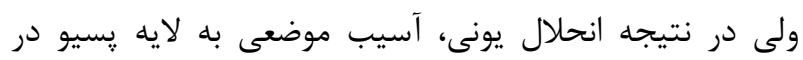

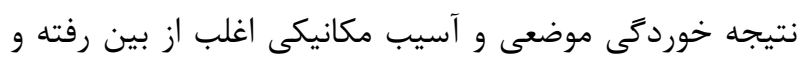

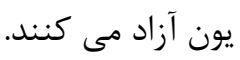
مطالعات اندكى در ارتباط با يسيو شدن شيميايى آليازها با استفاده محلول هاى شيمياى انجام شده است. تحقيقات اندى نشان دادند كه محلول هاى Na2SO4، Na3PO4 و NaNO3

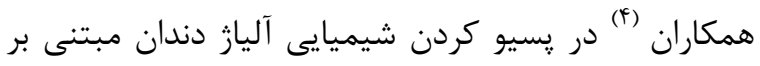

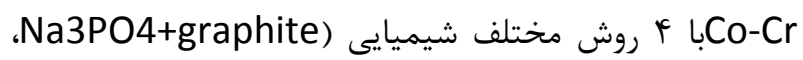
ra2 Na3PO4 Na2SO4tgraphite كه محلول Na2SO4 با كرافيت باعث بهبود قابل توجهى در

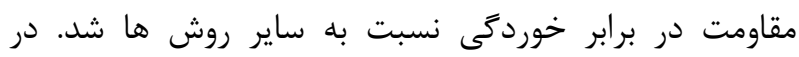
مطالعه حاضر نيز از روش غوطه ورى در محلول سولفات

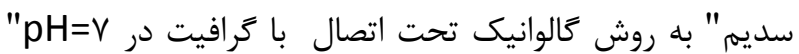
جهت يسيو كردن آلياز پايه كبالت-كرومFlexicast استفاده شد كه نتايجى مشابه با مطالعه Rylska و همكاران داشت. آنها برديه

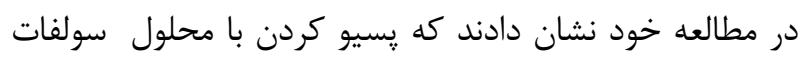




\section{References:}

1.Sarantopoulos DM, Beck KA, Holsen R, Berzins DW. Corrosion of $\mathrm{CoCr}$ and $\mathrm{NiCr}$ dental alloys alloyed with palladium. J Prosthet Dent 2011; 105(1): 35-43.

2.Ameer MA, Khamis E, Al-Motlaq M. Electochemical behaviour of recasting $\mathrm{Ni}-\mathrm{Cr}$ and $\mathrm{Co}-\mathrm{Cr}$ non-precious dental alloys. Corrosion Science 2004; 46(11): 28252836.

3.Geis-Gerstorfer J. In vitro corrosion measurements of dental alloys. J Dent 1994; 22(4): 247-51.

4.RYLSKA DA, SOKOLOWSKI GZ, SOKOLOWSKI JY , LUKOMSKA MA - SZYMANSKA Chemical passivation as a method of improveing the electrochemical corrosion resistance of $\mathrm{Co}-\mathrm{Cr}$ based dental alloy. Acta Bioeng Biomech 2017, 19(2):78-73.

5.Mutlu-sagesen L,Ergun G,Karabulut E.Ion release from metal-ceramic alloys in different media. Dent Mater J 2011;30(5):598-610.

6.Matkovic T, Matkovic P, Malina J. Effects of $\mathrm{Ni}$ and Mo on the microstructure and some other properties of Co-Cr dental alloys. JALCOM 2004; 366(1-2): 293-297.

7.Espeik S.Corrosion of base metal alloys in vitro.Acta Odontol Scand 1977;36:113-117.

8.Mc Ginley EL, Coleman DC, Moran GP, Fleming GJ.Effect of surface finishing conditions on the biocampatibility of a Nickel-Chromium dental casting alloy.Dent Mater 2011;27(7):637-50.

9.Jakovljević S, Alar V, Ivanković A .Electrochemical Behaviour of PACVD TiN-Coated CoCrMo Medical Alloy. Metals 2017; 7(7): 231.

10.Kirchgeorg T, Weinberg I, Hörnig M, Baier R, Schmid MJ, Brockmeyer B.Emissions from corrosion protection systems of offshore wind farms: Evaluation of the potential impact on the marine environment. Mar Pollut Bull 2018; 136:257-268.

11.Fukushima A1, Mayanagi G2, Sasaki K3, Takahashi N4Corrosive effects of fluoride on titanium under artificial biofilm. J Prosthodont Res 2019;62(1):104-109 12.Denizoğlu S, Duymuş ZY, Akyalçin S. Evaluation of ion release from two base-metal alloys at various $\mathrm{pH}$ levels. J Int Med Res 2004; 32(1): 33-8.

13.Rincic Mlinaric M1, Karlovic S2, Ciganj Z3, Acev DP4, Pavlic A4, Spalj S5. Oral antiseptics and nickeltitanium alloys: mechanical and chemical effects of interaction. Odontology 2019; 107(2):150-157.

14.Ragone V1, Canciani E2, Biffi CA3, D'Ambrosi R4, Sanvito R1, Dellavia C2, Galliera E5,6. CoCrMo alloys ions release behavior by TiNbN coating: an in vitro study. Biomed Microdevices 2019 ;21(3):61.

15.Huang Y1, Hu JY, Liu YP, Zhao DY, Yu YC, Bi W. The effect of $\mathrm{C}-\mathrm{SiO} 2$ composite films on corrosion resistance of dental Co-Cr alloy. Shanghai Kou Qiang Yi Xue 2016; 25(5):542-547.

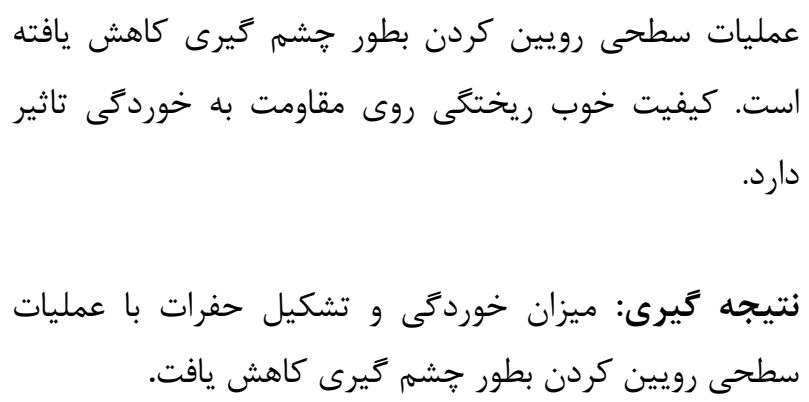

